\title{
Research on Influence of Investors' Willingness to Invest in Equity Crowdfund
}

\author{
Yongming Pan ${ }^{a}$, Yayun Liu ${ }^{b}$ \\ Tianjin University of Technology, Tianjin300384, China; \\ a514555361@qq.com, b13920912772@163.com
}

Keywords: subjective norms; perceived risk; perceived value; investor innovation; willingness to invest.

\begin{abstract}
From the perspective of equity crowdfunding investors' cognition, the concept models of perceived risk, subjective norm, perceived value and investment willingness are constructed by referring to relevant theories such as planned behavior and individual innovation. The results of the study show that subjective norms of investors have a significant positive impact on investment willingness through perceived value; investors perceived negative influence on investment willingness. Through the analysis of the development status of the equity crowdfunding market and the influence factors of investors' investment intention, the current theoretical research on investment decision-making is refined. At the same time, individual investor's willingness to invest in equity crowdfunding projects is analyzed from the perspective of individual cognition and equity crowdfunding is enhanced. Project effectiveness and relevance.
\end{abstract}

\section{Introduction}

The current investment and financing model has been overturned in the thriving information age of the Internet, big data, and cloud computing. Different from the original investment models such as the purchase of securities direct investment and indirect investment in the form of bank deposits and purchase of wealth management products, the "Internet finance model" is a new investment model that uses the Internet platform to pool public funds, channels, and resources. , Ability to provide necessary financial assistance for SMEs to carry out certain activities during the start-up period or for individuals to carry out certain projects. Equity crowdfunding is one of them. It means that the company uses the online crowdfunding platform to raise funds from ordinary investors through internet channels. Investors subscribe for shares, become shareholders of the company and receive financing from future earnings, and are financing for small and micro enterprises in China. Models and effective ways of financial service innovation. However, there are also many problems in the rapid development of equity crowdfunding, as crowdfunding investors are mostly ordinary individual non-professional investors, and due to the asymmetry of investment and financing information, investors' investment risks increase and uncertainty. Increased, less willingness to invest. Therefore, this paper studies the investment willingness of equity crowdfunded investors, explores the factors of investment willingness, tries to theoretically enrich the theory of domestic crowdfunding investment willingness; in practice, it identifies the investment psychology of crowdfunding investors and improves the financing success. Rate, to understand the equity crowdfunding market investment behavior has important practical significance.

\section{Organization of the Text}

This article mainly analyzes and analyzes the equity crowdfunding market in China at this stage. Through literature analysis and review, it explores the influencing factors of investor's investment willingness. The first part introduces the innovative application of equity crowdfunding as internet inclusive finance in the context of internet and big data. There are also many problems in the rapid development, sorting out its background, concepts, development status and problems, and eliciting 
individual investors' equity the exploration of crowdfunding project investment will help guide the crowdfunding platform to more accurately and efficiently understand the needs of investors in project financing, and increase the success rate of project crowdfunding. The second part briefly discusses the organizational structure of this article; the third part is adopted. The relevant research and literature review at home and abroad were used to discuss the impact of the three dimensions of subjective norms, perceived value, and perceived risk on investment willingness; the fourth part summarized the research conclusions of this article and extracted the theoretical construction of the study. And management inspiration, with a view to the practice of the equity crowdfunding project for reference.

\section{Literature References}

\subsection{The Impact of Subjective Norms on Investment Willingness}

Subjective norms refer to the degree of influence of social customs and their communities on individuals' willingness to act, that is, the influence of social groups on individual attitudes and decision-making when people express opinions and attitudes or choose actions [1]. Evers first proposed the "prosocial" of crowdfunding in 2012. He believed that crowdfunding participants are vulnerable to social factors, perceptions, and the value judgment of the surrounding people [2]. From the perspective of social identity, Chen Yanyan and others found that group sentiment is an important factor affecting investors' participation in crowdfunding [3]. Therefore, in the past research, the subjective norms of equity crowdfunding investors are positively influenced by the three dimensions of leader effect, cohort effect and social identity.

\subsection{Impact of Perceived Risk on Investment Willingness}

The definition of perceived risk was first extended by Bauer from psychology in 1960. He believes that the possibility of uncertainty and adverse consequences perceived by consumers when purchasing a product or service is the original concept of perceived risk. [4]. Norbert found that the perceived risk of user perception is one of the main factors that hinder users' online transactions [5]. Xu Chenfei in the crowdfunding website user participation research, the perceived risk is defined as investors can self-consciously may be detrimental to their own interests of the matter, and personal information leakage, project financing is successful but failed to complete as perceived risk measurement Variable [6]. Drawing on the research of domestic and foreign scholars, the study believes that investors' perception of risks that may be detrimental to their own interests will hinder investors' willingness to invest.

\subsection{The Impact of Subjective Norms and Perceived Risks on Perceived Value}

Kuppuswamy and Bayus pointed out that social influencing factors greatly influence investors' evaluation of crowdfunding projects [7]. Equity crowdfunding is an investment behavior with long investment cycle and great uncertainty. The problem of information asymmetry makes it more difficult for investors to make decisions. The value judgment of investors is easily influenced by the surrounding population. Holbrook and Corfman's study found that perceptional benefit is a subjective feeling of the user. Different perceived risks make users feel different about the value of the product or service [8]. For equity crowdfunding, the instability of project equity returns and the success of the project's products or services are investors' most direct perceived risks, affecting investors' value judgments. In summary, most equity crowdfunded investors are non-professional public investors. Their own investment experience is insufficient. Affected by the psychology of profit-making, it is easy to generate high-value expectations for projects with high support for the public, and to avoid attitudes toward projects with large perceived risks. The perceived value of investors for crowdfunding projects will be affected by their subjective norms. The perceived risks of investors will negatively affect the perceived value of investors.

\subsection{Influence of Perceived Value on Investment Willingness}

Zaithaml believes that perceived value is the overall evaluation of the effectiveness of a product or service after weighing the benefit that the customer can recognize with the cost of acquiring the product or service [9]. Zeng Jianghong and others believe that various projects provided on 
crowdfunding platforms can provide investors with economic value, social value, and functional value to varying degrees. When one or more of these values meet the needs of investors, they will Willing to participate in investment [10]. Equity crowdfunding investors are project participants to a certain extent, and together with the project parties to complete the value creation of crowdfunding projects, investors' cognition of the value of equity crowdfunding projects is the main driving force for investors to participate in investment, and investors' perceived value positively influences investors' willingness to invest.

In summary, the conceptual model is shown in Figure 1.

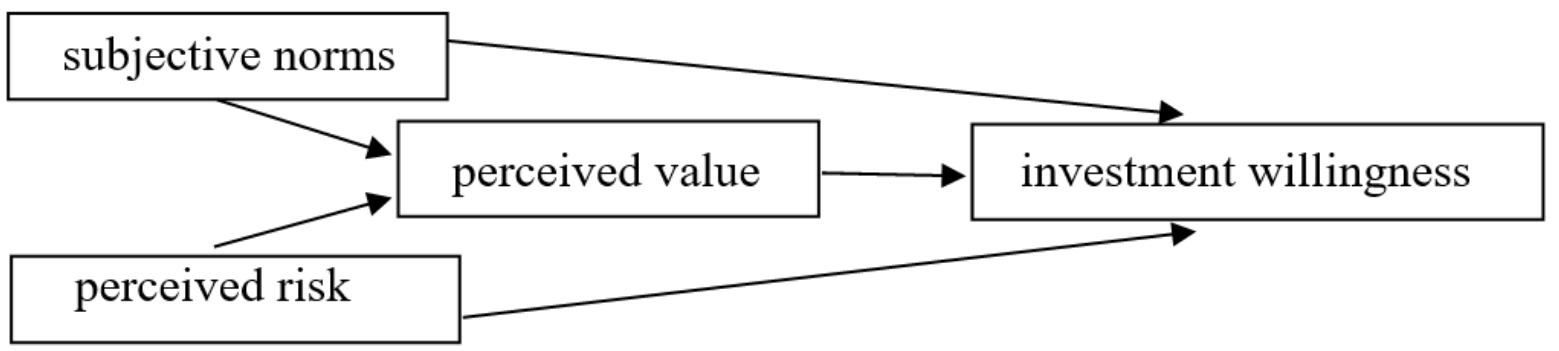

Fig. 1. Conceptual model

\section{Summary}

First of all, from the theoretical construction, this paper finds that the stronger the subjective norms of investors, the stronger their willingness to invest in equity crowdfunding projects. When investors consider whether or not to invest in an equity crowdfunding project, the social norms, mainstream opinions, and market leader opinions that investors perceive on their own will have a great influence on investors' willingness to invest. This paper finds that the greater the perceived risk of equity crowdfunded investors is, the smaller the investment willingness is. The investor basically belongs to a single risk aversion, and studies with $\mathrm{Xu}$ Chenfei and others on the negative impact of perceived risk on user participation in crowdfunding networks. Consistent [6]. In addition, like previous scholars' researches, perceived value is an important basis for the overall evaluation of various benefits and efforts in the process of individual cognition. The higher the perceived value, the stronger the investor's willingness to invest. This paper verifies the mediating effect of perceived value on subjective norms and investment willingness. The stronger the subjective norms of investors are, the higher the perceived value of equity crowdfunding projects is, and the stronger the willingness to invest finally. This is because in the process of making investment decisions, investors are eager to get a reliable basis for accurate judgments on the value of projects. Often, the stronger the subjective norms, the more vulnerable the investors are to the influence of market value orientation, which echoes the mainstream view of the market or opinion leaders. Value judgments, so investors' perceived value is subject to their subjective norms.

Second, in the management practice, the following points should be noted for the equity crowdfunding platform: (1) As a new type of investment model, equity crowdfunding is popular among investors, but it does not change the financial risk attributes. The platform shall strictly review the project party's financing information, set the project party's equity ownership threshold, firmly bind the project party and the investor's interests, and help reduce the investor's perceived risk while assisting the project party in financing. (2) The equity crowdfunding platform itself is not only an investment platform, a financing platform, but also should be a project promotion platform and a communication platform. It should pay more attention to the platform effect to control public opinion guidance and mainstream opinions, and guide investors to make reasonable value judgments. To prevent investors from blindly following the cause of unnecessary losses and affecting the financing of other quality projects. 


\section{Acknowledgments}

We would like to thank the National Social Science Fund Project: Research on the financing path and mechanism of small and medium-sized enterprise groups for SMEs (11BGL023) supports this work.

\section{References}

[1]. Ajzen I, Fishbein M. Attitude-behavior relations: A theoretical analysis and review of empirical research. [J]. Psychological Bulletin, 1977, 84(5):888-918.

[2]. Evers, M., Main drivers of crowdfunding success: a conceptual framework and empirical analysis. Master Thesis Rotterdam school of Management, Erasmus University,No.302538, 2012.

[3]. Chen Yanyan, Wang Juan, Zhang Yana. The Role of Social Identity in Returning Crowdfunding to Investor Decision-making: An Analysis Based on Group Emotion and Effectiveness Path [J]. Business Studies, 2017, (03): 127-135.

[4]. Bauer R.A. Consumer Behavior as Risk Taking[M]//Hancock R.S.(Ed.), Dynamic Marketing for A Changing World. Chi-cago: American Marketing Association,1960.

[5]. Norbert Schwarz. Emotion, cognition, and decision making[J]. Cognition \& Emotion, 2000, 14(4):433-440.

[6]. XU Chenfei, CHEN Hao. Research on the Influencing Factors of Crowdfunding Website User Participation: Taking Crowdfunding Network as an Example [J]. Journal of Information, 2015, (11): $175-182+174$.

[7]. Kuppuswamy V, Bayus B L. Crowdfunding Creative Ideas: The Dynamics of Project Backers in Kickstarter[J]. Social Science Electronic Publishing, 2013.

[8]. Holbrook M B, Corfman K P. Quality and Other Types of Value in The Consumption Experience[D]. Columbia University, 1983.

[9]. Zaithaml. Valerie: Consumer Perceptions of Price, Quality, and Value: A Means-End Model and Synthesis of Evidence. Journal of Marketing, 1988, 52(7):2-22.

[10]. Zeng Jianghong, Chen Siqi. Research on the relationship between value co-creation and satisfaction of project proponents under the crowdfunding model[J]. Chinese Journal of Management, 2016, (09):1383-1391. 